\title{
Satua I Srabena I Srabeni: Kajian Sastra Antropologis
}

\author{
Ni Komang Dewi Juliana*1, Ni Made Suryati ${ }^{2}$, Luh Putu Puspawati ${ }^{3}$ \\ ${ }^{[123]}$ Prodi Sastra Bali, Fakultas Ilmu Budaya, Universitas Udayana \\ ${ }^{1}$ [julsmith.js@gmail.com] [2 Suryati.jirnaya@yahoo.com] \\ ${ }^{3}$ [puspawati1960@yahoo.co.id] \\ *Coresponding Author
}

\begin{abstract}
The study of Satua I Srabeni I Srabena discusses the analysis of literary structure and anthropology. This analysis aims to reveal the building structures and values of Balinese culture embodied in Satua I Srabena I Srabeni.This research uses structural theory, text theory, and theory of Literary Anthropology. Methods and techniques used in this study are divided into three stages, namely 1) methods and techniques of data provision using simak method assisted by transcription techniques, record techniques, and translation techniques, 2) methods and techniques of data analysis using qualitative methods and descriptive analytic techniques, 3) methods and techniques of presenting the results of data analysis using informal methods and deductive and inductive techniques. The result of this research is narrative strutur which includes eight incident, using straight groove and groove is divided into five stages, namely: situation stage, generating circumstances stage, rising action stage, climax stage, and denouement stage. Characters and characterizations are divided into three namely: the main character is I Srabena I Srabeni, secondary figures namely Father, and complementary figures (complementary) ie a couple husband, wife of Anak Agung, Anak Agung, wife Jin, Jin. Background is divided into three, namely: the background of the place that is on the road, jumah, gerobag, park, alase, diwangan, punyan bingin, ampike, and pasisi, background time is peteng, ibi sanja, and weak and background atmosphere angry atmosphere, , longing, anxiety, fear, and threatening atmosphere. The theme of women, about women in good behavior should be done by women and contained a mandate on how to respect women and behave well in life. The results of the literary anthropological research in this satua reveal the values of the culture contained, namely the value of vital, social values, ethical values, human values, sacred values, and the value of rwa Bhinneda contained in the four elements of culture in the story.
\end{abstract}

Keywords: satua, structure and literary anthropology.

\begin{abstract}
Abstrak
Penelitian terhadap Satua I Srabeni I Srabena ini membahas tentang analisis struktur dan antropologi sastra. Analisis ini mempunyai tujuan untuk mengungkapkan struktur yang membangun dan nilai kebudayaan Bali yang terkandung dalam Satua I Srabena I Srabeni. Penelitian ini menggunakan teori struktural, teori teks, dan teori Antropologi Sastra. Metode dan teknik yang digunakan dalam penelitian ini dibagi menjadi tiga tahap, yakni 1) metode dan teknik penyediaan data menggunakan metode simak dibantu dengan teknik transkripsi, teknik catat, dan teknik terjemahan, 2) metode dan teknik analisis data menggunakan metode kualitatif dan teknik deskriptif analitik, 3) metode dan teknik penyajian hasil analisis data menggunakan metode informal dan teknik
\end{abstract}


deduktif dan induktif. Hasil yang diperoleh dari penelitian ini yakni strutur naratif yang meliputi delapan insiden, menggunakan alur lurus dan alur dibagi menjadi lima tahap, yakni: tahap situation, tahap generating circumstances, tahap rising action, tahap climax, dan tahap denouement. Tokoh dan penokohan dibagi menjadi tiga yakni: tokoh utama yaitu I Srabena I Srabeni, tokoh sekunder yaitu Bapa, dan tokoh pelengkap (komplementer) yaitu sepasang suami istri, istri Anak Agung, Anak Agung, istri Jin, Jin. Latar dibagi menjadi tiga, yaitu: latar tempat yaitu di jalan, jumah, gerobag, taman, alase, diwangan, punyan bingin, di ampike, dan pasisi, latar waktu yaitu peteng, ibi sanja, dan lemah dan latar suasana yaitu suasana marah, kecewa, rindu, gelisah, takut, dan suasana mengancam. Tema yang terdapat yakni wanita, mengenai wanita dalam bertingkah laku yang baik yang seharusnya dilakukan oleh wanita serta terkandung amanat mengenai bagaimana menghargai wanita dan berprilaku yang baik dalam kehidupan. Hasil penelitian antropologi sastra pada satua ini mengungkapkan nilai kebudayaan yang terkandung, yakni nilai vital, nilai sosial, nilai etika, nilai kemanusiaan, nilai keramat, dan nilai rwa Bhinneda yang tertuang dalam empat unsur kebudayaan dalam cerita.

Kata Kunci: satua, struktur dan antropologi sastra.

\section{Pendahuluan}

Representasi gambaran kehidupan manusia tertuang dalam sebuah karya sastra. Berbagai problematika dan dinamika kehidupan disajikan melalui jalinan kisah kehidupan para tokoh di dalamnya. Sebagai sebuah karya dengan struktur pembentuk sebagai unsur artistik, di dalam karya sastra juga tercermin berbagai aspek kehidupan manusia. Berbagai aspek kehidupan tersebut tergambar, baik secara fisik, psikologis, maupun sosial budaya.

Pembicaraan karya sastra dari sudut antropologi sastra merupakan hal yang baru dalam penelitian karya sastra dan merupakan model pendekatan interdisiplin yang relatif baru serta belum termasuk sebagai salah satu mata kuliah. Pendekatan antropologi terhadap sebuah karya sastra sebenarnya sudah pernah dilakukan oleh beberapa peneliti. Hal ini mungkin disebabkan oleh dominasi pendekatan sosiologi sastra karena menganggap bahwa hal-hal yang bersifat antropologis dalam sebuah karya sastra merupakan wilayah kajian sosiologi sastra.
Oleh karena sedikit sekali buku yang ditemukan yang membicarakan tentang antropologi sastra, maka dalam analisis antropologi sastra dalam penelitian ini mengacu pada pandanganpandangan Prof. Dr. I Nyoman Kutha Ratna,S.U. yang dipakai sebagai pijakan. Pandangan-pandangannya tersebut ada dalam bukunya berjudul Antropologi Sastra Peranan Unsur-unsur Kebudayaan dan Proses Kreatif (2011). Antropologi sastra adalah ilmu pengetahuan mengenai manusia dalam masyarakat (Ratna, 2004: 63). Penelitian satua ini peneliti menggunakan satua yang diperoleh di Museum Bali sebagai data primer. Satua I Srabena I Srabeni ini sangat menarik untuk diteliti dan dijadikan objek penelitian yang dilihat dari keseluruhan satua tersebut. Satua ini menggambarkan bagaimana tokoh di dalamnya melakukan perselingkuhan dan tipu muslihat yang dianggap sebagai suatu kebenaran dalam mencapai tujuan yang diinginkan. Setiap peristiwa demi peristiwa yang dilakukan oleh para tokoh di dalamnya mencerminkan tingkah laku serta kebiasaan manusia atau budaya yang berkembang pada saat itu yang digunakan oleh pengarang 
menyampaikan pesan yang ingin disampaikan kepada pembaca dengan penyajian yang berbeda yang nantinya setiap peristiwa yang terjadi pada karya sastra tersebut akan dibandingkan dengan budaya masa sekarang dengan menggunakan analisis antropologi sastra. Peneliti mengambil Satua I Srabena I Srabeni karena sebelumnya satua ini belum pernah digunakan sebagai objek penelitian dan peneliti juga ingin menggali lebih dalam dan khusus mengenai nilai kebudayaan Bali yang ada di dalamnya yakni nilai etika yang ada dimasyarakat dalam karya tersebut, nilai sosial dalam satua, nilai keramat serta nilai rwa Bhinneda yang tertuang pada alur cerita dengan menggunakan analisis antropologi sastra dengan judul penelitian yaitu "Satua I Srabena I Srabeni: Kajian Sastra Antropologis".

\section{Pokok Permasalahan}

1. Bagaimakah struktur Satua I Srabena I Srabeni?

2. Nilai kebudayaan Bali apakah yang terdapat pada Satua I Srabena I Srabeni?

\section{Tujuan Penelitian \\ Tujuan Umum}

Tujuan umum penelitian ini adalah untuk mempelajari dan mengambangkan salah satu kekayaan budaya Bali dalam bentuk satua sehingga masyarakat bisa melestarikan kebudayan yang terkandung dalam satua itu sendiri serta mengembangkan kebudayaan Bali yang terdapat pada satua ini sebagai suatu kekayaan daerah Bali. Serta menuangkan sebuah kajian baru yang masih sedikit peminatnya terutama kajian antropologi sastra sebagai motivasi untuk mengembangkan kajian baru dalam dunia sastra sebagai bentuk variasi.

\section{Tujuan Khusus}

1. Untuk mendeskripsikan aspekaspek struktur yang membangun Satua I Srabena I Srabeni.

2. Untuk mengetahui nilai-nilai kebudayan Bali yang tertuang dalam Satua I Srabena I Srabeni yang berhubungan dengan beberapa unsur kebudayaan secara universal dari ketujuh unsur-unsur kebudayaan secara universal yang ada sehingga dari sana dapat memperoleh nilai-nilai kebudayaan Bali yang terkandung yakni nilai etika pada masyarakat, nilai sosial, nilai kemanusiaan, nilai keramat serta nilai rwa Bhinneda yang terdapat pada satua ini.

\section{Metode Penelitian \\ Metode dan Teknik Penyediaan Data}

Metode dan teknik penyajian data pada penelitian ini dilakukan dengan metode simak yaitu menyimak teks Satua I Srabena I Srabeni yang dijadikan objek dalam penelitian ini. Menyimak adalah suatu proses kegiatan mendengarkan lambang-lambang lisan dengan penuh perhatian, pemahaman, apresiasi, serta interpretasi untuk memperoleh informasi, menangkap isi atau pesan serta memahami makna komunikasi yang telah disampaikan oleh pembicara melalui ujaran atau bahasa lisan (Tarigan, 1984: 28). Teknik yang digunakan dalam tahapan penelitian ini adalah teknik pencatatan dilanjutkan dengan teknik transliterasi dan terjemahan. Teknik catat, yaitu data yang diperoleh dari penyimakan kemudian dicatat, sesuai dengan data yang diperlukan dalam penelitian serta pencatatan yang digunakan untuk mencatat data yang berkaitan dengan identifikasi sumber kajian maupun data lain sebagai pendukung penelitian ini. Teknik transliterasi yang dilakukan yakni ejaan 
satua dari Ejaan Soewandi dalam bahasa Bali kemudian ditransliterasi ke ejaan bahasa Bali yang sesuai dengan ejaan yang disempurnakan, kemudian dilanjutkan dengan teknik terjemahan yakni diterjemahkan ke dalam Bahasa Indonesia. Menerjemahkan dilakukan perkata dalam satu kalimat kemudian dilanjutkan perkalimat. Dalam hal ini terjemahan dilakukan secara harfiah dan idiomatis. Terjemahan harfiah adalah terjemahan secara leksikal murni. Terjemahan idiomatis merupakan terjemahan yang menggunakan bentuk bahasa sasaran yang wajar, baik kontruksi gramatikalnya maupun pemilihan unsur leksikalnya (Larson, 1989: 17).

\section{Metode dan Teknik Analisis Data}

Tahap ini dilakukan dengan menganalisis data yang telah dikumpulkan dengan menggunakan metode hermeneutik dan kualitatif. Metode hermeneutik dilakukan untuk menafsirkan atau menginterpretasikan Satua I Srabena I Srabeni yang telah disimak. Metode ini digunakan untuk mengidentifikasikan nilai kebudayaan Bali Satua I Srabena I Srabeni sedangkan metode kualitatif adalah suatu metode yang memberikan perhatian terhadap data ilmiah, data dalam hubungannya dengan keberadaannya. Teknik yang digunakan adalah teknik deskriptif analitik yakni dengan cara mendeskripsikan fakta-fakta yang disusul dengan melakukan analisis atau menguraikan data dan digunakan dengan pertimbangan bahwa suatu analisis didasarkan atas deskripsi permasalahan secara keseluruhan.

\section{Metode dan Teknik Penyajian Hasil}

\section{Analisis Data}

Dalam tahapan ini, hasil analisis disajikan dengan metode informal.
Metode informal digunakan untuk menyajikan hasil analisis data dalam bentuk kata-kata biasa serta mudah dipahami dan bukan dalam bentuk angkaangka. Tahap ini didukung dengan menggunakan teknik deduktif dan teknik induktif.

\section{Pembahasan}

\section{Struktur Teks Satua I Srabena I Srabeni: Kajian Sastra Antropologis}

\section{Plot/alur Satua I Srabena I Srabeni: Kajian Sastra Antropologis}

Plot merupakan cerminan, atau bahkan berupa perjalanan tingkah laku para tokoh dalam bertindak, berpikir, berasa, dan bersikap dalam menghadapi berbagai masalah kehidupan (Nurgiyantoro, 2012: 114), dalam teks Satua I Srabena I Srabeni dilihat dari rangkaian peristiwa-peristiwa yang terdapat di dalamnya menggunakan alur maju selanjutnya dipaparkan secara lengkap mengenai alur cerita teks Satua I Srabena I Srabeni yakni diawali dengan tahap penyituasian (situation) yaitu bagaimana keinginan dari tokoh $I$ Srabena dan I Srabeni ingin menjadi seorang yang agung, sehingga dengan keinginan mereka tersebut mendorong mereka menanyakan bagaimana cara untuk menjadi seorang yang agung kepada ayahnya, seperti pada kutipan berikut.

"Ada kacerita anak manyama ajaka dadua, ne kelihan madan I Srabena adinne madan I Srabeni. Ngomong I Srabena I Srabeni teken bapanne: "Bapa bapa icang dot pesan dadi agung, jenengang ja icang "Anak Agung". Masaut bapanne: "Beh cening, keweh pesan anake lakar dadi agung, yan tonden maan 
ngamitrain anak luh suba ngelah kurenan, tur apang di arepan ane muani ngamitrain, tusing ja dadi jeneng agung”. Mara keto munyin bapanne, masaut I Srabena I Srabeni: "Nah bapa keto ja keto" (halaman 1 alenia $1)$.

Terjemahan:

"Ada sebuah cerita dua bersaudara, anak pertama bernama Si Srabena dan adiknya bernama Si Srabeni. Lalu Si Srabena Si Srabeni berkata kepada ayahnya: "Ayah ayah aku ingin sekali menjadi Agung, beritahu aku bagaimana menjadi "Anak Agung". Kemudian ayahnya menjawab: "Wah itu sulit anakku, sangat sulit jika ingin menjadi agung, jika belum dapat berselingkuh dengan seorang wanita yang sudah bersuami dan harus di hadapan sang suamilah melakukan perselingkuhan itu, jika belum demikian belum bisa menjadi agung". Setelah ayahnya berkata seperti itu, Si Srabena Si Srabeni menjawab: "Iya ayah baiklah jika begitu".

Pada tahap generating circumstances atau tahap pemunculan konflik yaitu diawali dengan tokoh $I$ Srabena dan I Srabeni yang telah berhasil melakukan perselingkuhan dan melaporkan kejadian yang sudah ia lakukan kepada ayahnya, namun bagi sang ayah ini belum cukup jika ingin menjadi seorang yang agung, untuk itu muncul konflik awal dari tokoh sang ayah kepada tokoh I Srabena dan I Srabeni yang menginginkan anaknya untuk melakukan perselingkuhan kembali, seperti kutipan berikut.
"Suba suud mulih lantas I Srabena. Suba jene teked jumah, morahan lantas teken bapanne: "Bapa, suba maan icang ngamitrain kurenan anak, dong jenengang icang agung”. Masaut bapanne: "Dijanne tongos caine matemu ajak anake luh?". "Di duur grobage". Keto pesaut I Srabena, "Ah lamun keto tusing kanggo, kemu jani ngalih, apang tingalina baan muanine" (halaman 1-2 alenia 2 baris ke 1216).

Terjemahan :

"Setelah selesai kemudian $\mathrm{Si}$ Srabena pulang. Sampai di rumahnya lalu berkata dengan ayahnya: "Ayah, aku sudah dapat berselingkuh dengan seorang wanita yang sudah bersuami, untuk itu aku sudah bisa disebut agung?". Ayahnya menjawab: "dimana kau bertemu dengan wanita itu?". "di atas gerobag". Begitulah Si Srabena menjawab, "Ah.. jika seperti itu belum bisa kamu disebut agung, kesana kembali agar dilihat oleh suami wanita itu".

Pada tahap Rising action (peningkatan konflik) konflik batin yang dirasakan oleh tokoh I Srabena dan I Srabeni dan pada akhirnya mereka berhasil menjadi seorang yang agung dengan melakukan perselingkuhan yang sesuai dengan saran dari sang ayah. Tokoh I Srabena dan I Srabeni akhirnya masing-masing menikah dengan keseratus istri mereka. Karena jarak yang memisahkan mereka konflik batin ingin bertemu semakin kuat, seperti kutipan berikut.

"Kacerita macepuk lantas ya di jalan, ditu lantas ya pada mareren, tur saling takonin. 
Masaut adinne: "Beh beli icang makeneh mulih kumah beline, dening icang iseng pesan teken beli". Mara keto munyin adine, lantas ajaka mulihne teken belinne, kacerita neked kone suba jumah belinne (halaman 3 alenia 8 baris ke 1-4).

Terjemahan:

"Diceritakan mereka berdua bertemu di perjalanan, di sana mereka berhenti dan saling bertegur sapa. Adiknya berkata: "Yah kakak, aku ingin ke rumahmu, karena aku ingin bertemu denganmu". Setelah adiknya berkata seperti itu kemudian di ajak pulang ke rumah kakaknya dan sampailah mereka. Karena sudah malam kemudian Si Srabeni menginap di sana".

Pada tahap klimaks (climax) tahap ini di dukung sebelumnya dengan kedatangan dan kerinduan masingmasing tokoh I Srabena dan I Srabeni yang dilanjutkan dengan tahap klimaks yaitu tokoh I Srabena yang mengetahui dan melihat sendiri bagaimana keseratus istrinya berselingkuh dengan laki-laki lain, di sana juga terungkap hal yang sama terjadi pada saudaranya yaitu $I$ Srabeni yang terlebih dahulu mengetahui keseratus istrinya telah berselingkuh namun ia pendam, seperti kutipan berikut.

"Sasubane neked jumah, nget makejang kurenane dapetanga ngajak anak muani. Ditu lantas gedeg I Srabena tur agelina kurenane muah ane ngamitrain. Malaib pablesat lantas anake ngamitrain. Mara keto undukne kurenan I Srabenane ngomong adinne: "Beh beli, tiang masih kene ibi sanja dugas tiange ngorahang meju, sujatine tiang mulih. Teked jumah, dapetang tiang kurenan tiange makejang ngajak anak muani pada mabesik" (halaman 4 alenia 10 baris ke 4-9)".

Terjemahan:

"Kembali mereka ke rumah dan sesampainya di rumah Si Srabena dilihat semua istrinya sedang bersama lelaki lain. Di sana marah Si Srabena dan diusirlah istrinya serta para selingkuhannya. Para lelaki selingkuhan istrinya lari tunggang langgang. Setelah melihat kejadian itu Si Srabeni berkata kepada kakaknya:" Kakak, aku juga kemarin malam saat aku ijin untuk buang air besar, sebenarnya aku pulang ke rumah. Sesampai di rumah aku melihat istriku semua bersama lelaki lain".

Tahap akhir, yaitu tahap penyelesaian (denouement), yang terjadi ketika ketika mengetahui masing-masing keseratus istrinya melakukan perselingkuhan tokoh I Srabena dan I Srabeni akhirnya pergi ke hutan, di hutan mereka bertemu dengan sepasang Jin yang dalam cerita Istri Jin memaksa mereka untuk melakukan perselingkuhan dengan Istri Jin tersebut. Tahap penyelesaian ini pada akhirnya tertuang jelas pada saat tokoh I Srabena dan I Srabeni kembali kepada masing-masing keseratus istri mereka, seperti pada kutipan berikut.

"Masaut belinne: "Beh saja adi, yan keto jalan suba alih buin kurenan ideweke buin anggon kurenan". "Jalan". Mulih lantas neked jumahne, buin anggona kurenan laad kurenane ane suba 
(halaman 5 alenia 11 baris ke 2931)".

Terjemahan:

"Menjawab kakaknya: "Benar adikku, jika begitu mari kita pulang dan kembali kepada istri kita masing-masing". "Mari". Kemudian Si Srabena Si Srabeni pulang dan sesampainya di rumah, dijadikan istrinya kembali istri mereka".

\section{- Tokoh}

Tokoh cerita (character).

Menurut Abrams (1981: 20 dalam Nurgiyantoro, 2012: 165) adalah orangorang yang ditampilkan dalam suatu karya naratif atau drama yang oleh pembaca ditafsirkan memiliki kualitas moral dan kecenderungan tertentu seperti yang diekspresikan dalam ucapan dan apa yang dilakukan dalam tindakan.

Tokoh utama dakam satua ini adalah I Srabena dan I Srabeni kemudian tokoh sekunder yaitu Bapa, dilanjutkan dengan tokoh pelengkap (komplementer) adalah sepasang suami istri, Anak Agung, Istri Anak Agung dan Jin serta Istri Jin yang keseluruhan tokoh dalam penokohannya dianalisis secara dramatik sehingga penyajian cerita menjadi lebih menarik.

\section{- Tema}

Menurut Nurgiyantoro, tema sebuah karya sastra selalu berkaitan dengan pengalaman kehidupan. Pemilihan tema-tema tertentu ke dalam sebuah cerita bersifat subyektif.Tema dalam Satua I Srabena I Srabeni adalah tentang wanita, karena dari awal cerita, pertengahan hingga klimaks dan tahap penyelesaian masalah yang dialami oleh para tokoh di dalamnya bercerita mengenai seorang wanita. Bagaimana wanita berperan, bersikap dan bertingkah laku serta memiliki cara berpikir yang digambarkan oleh pengarang. Sehingga tema yang diambil adalah mengenai wanita karena alur dan cerita lebih banyak mengungkapkan kejadian yang berhubungan dengan tokoh wanita dalam satua.

\section{- Latar}

Latar dalam karya fiksi tidak terbatas pada penempatan lokasi-lokasi tertentu atau yang bersifat fisik semata. Latar bisa berwujud tata cara, adat istiadat, kepercayaan, dan nilai-nilai yang berlaku di tempat yang bersangkutan (Nurgiyantoro, 2012: 217 - 218). Latar yang terdapat dalam Satua I Srabena I Srabeni adalah latar waktu, latar tempat dan latar suasana. Latar waktu dalam Satua I Srabena I Srabeni ini adalah peteng, ibi sanja dan lemah. Latar tempat yakni di jalan, jumah, gerobag, taman, alase, diwangan, punyan bingin, di ampike dan pasisi. Latar suasana yang diungkapkan adalah suasana marah, kecewa, rindu, gelisah, takut dan suasana mengancam.

\section{- Amanat}

Amanat merupakan pesan moral yang terkandung dalam sebuah karya sastra yang ingin disampaikan oleh pengarang kepada para pembaca atau penikmat karya sastra berupa nilai-nilai leluhur yang dapat dijadikan contoh atau teladan. mengamalkan beberapa ajaran pokok nilai-nilai kebudayaan yang sudah ada di Bali dengan memberikan contohcontoh dari setiap perbuatan buruk yang bisa dilakukan oleh semua orang. Dibalik setiap peristiwa dan tingkah laku tokoh memberikan amanat yang tersimpan dengan baik jika kita benar-benar menelaahnya. Bagaimana menghargai kedudukan seorang wanita, selanjutnya amanat yang diungkapkan mengenai kesadaran diri yang seharusnya dimiliki seseorang dalam hidup. Tidak dapat mempertimbangkan saran-saran atau masukan yang diterima dari segala arah sehingga langsung menelannya mentah- 
mentah, tetapi yang perlu dipelajari adalah kita bisa memposisikan diri untuk menyesuaikan dengan ajaran yang baik dan benar. Tentunya juga, amanat yang diungkapkan untuk mengingatkan setiap manusia pentingnya arti rasa bersyukur dengan apa yang telah dimiliki. Merasa bersyukur membuat kita tidak menghalalkan berbagai cara untuk mendapatkan sesuatu yang kita inginkan. Perlu adanya proses dan pedoman yang baik di dalam mendapatkan semua itu agar tidak melewati dari sebuah arti kebenaran. Dari cerita di atas juga kita dapat mempelajari dari nilai-nilai (khususnya nilai yang bersumber dari ajaran agama Hindu di Bali) yang ada di balik peristiwa yang disajikan oleh pengarang sehingga pembaca ikut dalam proses memaknai nilai yang ingin disampaikan oleh pengarang.

\section{- Nilai Kebudayaan Bali Satua I Srabena I Srabeni}

Menurut Koentjaraningrat (1997: 32) mengatakan bahwa dalam karya sastra tertuang deskripsi tentang nilainilai didaktik, antropologis, sosialreligius, dan nilai-nilai psikologis. Sistem nilai budaya adalah tingkat tertinggi dan paling abstrak dari adat istiadat. Nilai budaya terdiri dari konsep-konsep mengenai segala sesuatu yang dinilai berharga dan penting oleh warga masyarakat, sehingga dapat berfungsi sebagai suatu pedoman orientasi pada kehidupan warga masyarakat yang bersangkutan. Nilai budaya bersifat sangat umum, memiliki ruang lingkup yang sangat luas, dan biasanya sulit diterangkan secara rasional dan nyata. Hakekatnya nilai budaya telah meresap dalam jiwa seseorang dan diresapi oleh masyarakat sejak kecil, maka konsepkonsep budaya itu telah berakar dalam jiwanya, sehingga untuk mengganti nilai budaya yang telah dimiliki dengan nilai budaya lain diperlukan waktu yang lama (Koentjaraningrat, 1996 : 76).

\section{- Nilai Guna}

Nilai vital atau nilai guna yang dimaksudkan dalam satua ini adalah nilai yang meliputi berbagai konsepsi yang berkaitan dengan segala sesuatu yang berguna bagi manusia dalam melaksanakan berbagai aktivitas. Jika kita lihat dalam bentuk ajaran agama Hindu, nilai benda atau alat yang digunakan oleh umat Hindu sama halnya dengan menggunakan sarana banten atau sarana upacara dalam ritual yang dilaksanakan. Sebagai alat atau sarana yang digunakan yakni salah satunya adalah pohon bingin, gerobag menyatakan pohon bingin sebagai alat yang digunakan untuk tempat berlindung oleh tokoh $I$ Srabena dan I Srabeni. Dengan memanjat pohon bingin tersebut, kedua tokoh ini bersembunyi dari keberadaan Jin yang dengan tiba-tiba muncul sehingga membuat mereka ketakutan. Pohon bingin sangat akrab dengan budaya asli Hindu. Tumbuhan berbentuk pohon besar ini sering kali dianggap suci dan melindungi penduduk setempat. Sesaji sering diberikan di bawah pohon beringin yang telah tua dan berukuran besar karena dianggap sebagai tempat kekuatan magis berkumpul. Beberapa orang menganggap tempat di sekitar pohon beringin adalah tempat yang "angker" dan perlu dijauhi. Dalam beberapa pengertian yang berbeda, pohon bingin dianggap mempunyai makna melindungi dan mensejahterakan.

\section{- Nilai Sosial}

Nilai sosial yang terdapat pada karya sastra merupakan satu kesatuan yang dinamis dan bermakna, sebagai perwujudan nilai-nilai dan peristiwa penting pada zamannya. tokoh wanita telah membantu tokoh utama, sebagai 
manusia telah melakukan sikap saling tolong-menolong, namun yang perlu diperhatikan di dalam melakukan hal tersebut tokoh wanita seperti sudah merupakan hal yang biasa melakukan hal tersebut, atau pada karya tersebut mengungkapkan budaya yang memang dilakukan oleh pihak wanita tanpa sepengetahuan suaminya. Namun jika dilihat dari budaya sekarang hal tersebut jelas merupakan perbuatan yang tidak baik dikalangan masyarakat. Maka yang didapat adalah melakukan kegiatan yang baik dan benar untuk dapat membantu sesama sesuai dengan norma-norma yang berlaku. Dalam hal ini ajaran mengenai kesetiaan (setia kepada pasangan) terdapat pada ajaran satya yang artinya setia, jujur, dan benar sehingga menyebabkan orang lain menjadi senang yang tertuang dalam panca yama brata, yaitu lima macam pengendalian diri untuk mencapai kesempurnaan jasmani dan rohani (Supatra, 2004 : 9).

\section{- Nilai Etika}

Nilai etika yang terkandung dalam Satua I Srabena I Srabeni adalah pengarang mengharapkan kepada pembaca agar dapat menghormati orang tua serta memupuk hubungan harmonis antara sesama dan hidup saling menghormati. Selain itu, nilai etika yang ditekankan adalah bagaimana kita bisa melakukan hubungan seksual setelah melakukan perkawinan tidak dengan melakukannya diluar perkawinan karna memang sewajarnya melakukan hubungan seksual setelah perkawinan. Aturan mengenai etika atau tingkah laku dalam ajaran agama Hindu disebut dengan susila. Susila berasal dari dua kata yakni su artinya baik dan sila artinya tingkah laku. Dengan demikian susila berarti tingkah laku yang baik. Secara lebih luas dapat dipahami bahwa susila berarti perilaku atau etika yang baik dan budi luhur berdasarkan dharma.

\section{- Nilai Kemanusiaan}

Nilai kemanusiaan yang didapatkan dari Satua I Srabena I Srabeni. Dimana tokoh I Srabena dan I Srabeni melakukan pencarian status sosial demi menjadi seorang Agung yang dianggap bisa menunjang keberlangsungan hidupnya. Seperti yang di sarankan ayahnya, dianggap suatu yang benar dan sudah biasa untuk dilakukan yakni melakukan perselingkuhan dengan wanita yang telah bersuami demi mencapai tujuannya. Kesadaran humanis dalam nilai kemanusiaan juga muncul dalam percakapan antara tokoh melalui bahasa. Bahasa dianggap sebagai suatu komunikasi antar masyarakat yang mampu menghubungkan jurang pemisah atau perselisihan.

\section{- Nilai Keramat}

Tokoh I Srabena dan I Srabeni mengetahui bahwa yang keluar dari kepulan asap adalah makhluk halus berupa Jin sehingga membuat mereka sangat takut. Perasaan takut yang diungkapkan oleh kedua tokoh ini menunjukkan telah timbulnya sifat keramat yang kemudian dilanjutkan dengan tindakan mereka yang mencari perlindungan untuk diri mereka dengan naik ke atas pohon bringin karena mereka percaya akan adanya kekuatan sakti pada Jin tersebut yang bisa saja membahayakan nyawa mereka.

\section{- Nilai Rwa Bhinneda}

Keberadaan Jin dan Istri Jin mengungkapkan bagaimana pengarang menekankan bahwa kepercayaan masyarakat Bali terhadap alam sekalaniskala telah ada sejak dulu dan masih dipercayai sampai sekarang. Namun penampakan yang secara nyata seperti dalam satua mengenai keberadaan makhluk halus Jin tersebut jarang kita lihat pada budaya masa kini. Namun 
kepercayaan terhadap dua dunia yang ada pada masyarakat Bali masih ada sampai sekarang.

\section{Simpulan}

Satua I Srabena I Srabeni memiliki plot lurus atau alur maju terlihat dari rangkaian cerita dari keterkaitan objek sasaran cerita dari tahap awal hingga akhir. Tokoh utama Satua I Srabena I Srabeni yaitu I Srabena dan I Srabeni kemudian tokoh sekunder yaitu Bapa, dilanjutkan dengan tokoh pelengkap (komplementer) adalah sepasang suami istri, Anak Agung, Istri Anak Agung dan Jin serta Istri Jin yang keseluruhan tokoh dalam penokohannya dianalisis secara dramatik. Latar yang terdapat dalam Satua I Srabena I Srabeni adalah latar waktu, latar tempat dan latar suasana. Latar waktu dalam Satua I Srabena I Srabeni ini adalah peteng, ibi sanja dan lemah. Latar tempat yakni di jalan, jumah, gerobag, taman, alase, diwangan, punyan bingin, di ampike dan pasisi. Tema dari Satua I Srabena I Srabeni adalah tema tentang wanita. Dalam satua ini terdapat latar yaitu latar tempat, latar waktu, dan latar suasana. Nilai Kebudayaan Bali yang terkandung dalam Satua I Srabena I Srabeni yaitu nilai guna, nilai sosial, nilai etika, nilai kemanusiaan, nilai keramat, dan nilai rwa Bhinneda.

\section{Daftar Pustaka}

Koentjaraningrat. 2007. Pengantar Antropologi II (pokok-pokok

etnografi). Jakarta : Rineka Cipta.

Koentjaraningrat. 2009. Pengantar Ilmu Antropologi. Jakarta : Rineka Cipta

Luxemburg. Jan van dkk 1984. Pengantar Ilmu Sastra
(Terjemahan oleh Dick Hartoko dari Judul asli Inleiding in de Literaturwetencap). Jakarta: PT Gramedia.

Nurgiyantoro, Burhan. 1994: Teori Pengkajian Fiksi. Yogyakarta: Gadjah Mada University Press.

Ratna. I Nyoman Kutha. 2010. Metodelogi Penelitian: Kajian Budaya dan Ilmu Sosial Humaniora Pada Umumnya. Yogyakarta: Pustaka Pelajar.

Ratna, Nyoman Kutha. 2011. Antropologi Sastra (Peranan Unsur-unsur Kebudayaan dalam Proses Kreatif). Yogyakarta: Pustaka Pelajar.

Sibarani, Robert. 2007. Kearifan Lokal: Hakikat, Peran, dan Metode Tradisi Lisan. Edisi II. Jakarta: Asosiasi Tradisi Lisan (ATL).

Teeuw, A. 1984. Sastra dan Ilmu Sastra: Pengantar Teori Sastra. Jakarta: Pustaka Jaya.

Tarigan, Hendry Guntur. 1984. PrinsipPrinsip Dasar Sastra. Bandung: Angkasa. 